\title{
Estudos taxonômicos do gênero Calea (Asteraceae, Neurolaeneae) no estado da Bahia, Brasil
}

\author{
Taxonomic studies of the genus Calea (Asteraceae, Neurolaeneae) in Bahia state, Brazil
}

\author{
Nádia Roque $e^{1,3} \&$ Vitor Cavalcanti Carvalho ${ }^{2}$
}

\begin{abstract}
Resumo
Asteraceae é a maior família das angiospermas com ca. 24.000 espécies e 1600-1700 gêneros com distribuição cosmopolita. Calea L. contém aproximadamente 125 espécies que ocorrem em regiões tropicais e subtropicais do Novo Mundo, sendo que o maior número de espécies é registrado para o Brasil. O gênero é facilmente confundido com espécies de Aspilia e Wedelia. No entanto, Calea possui flores do raio pistiladas e pápus de páleas livres, enquanto em Aspilia as flores do raio são neutras e o pápus geralmente é aristado e Wedelia, por sua vez, possui flores do raio pistiladas e pápus coroniforme. O presente trabalho consiste no levantamento e estudo taxonômico das espécies de Calea no estado da Bahia. Para esse estudo, foram realizadas viagens de campo, além da análise de materiais depositados em herbários. No estudo realizado foram encontradas 10 espécies de Calea para o estado: C. angusta S.F. Blake, C. candolleana (Gardner) Baker, C. gardneriana Baker, C. harleyi H. Rob., C. microphylla (Gardner) Baker, C. morii H. Rob., C. pilosa Baker, C. pinheiroi H. Rob., C. purpurea G.M. Barroso e C. villosa Baker. As espécies diferenciam-se basicamente pelo arranjo da sinflorescência (número de capítulos e tamanho do pedúnculo), tipo de capítulo (radiado $\times$ discóide), receptáculo (paleáceo $\times$ epaleáceo), número de flores e tamanho das páleas do pápus. Dentre as espécies, $C$. angusta é restrita à vegetação arbustiva sobre dunas litorâneas (Bahia e Sergipe), C. candolleana é a espécie de maior distribuição geográfica no estado (BA, TO, GO, MG e PE), C. morii e C. pilosa são registradas apenas para o estado da Bahia. As demais espécies dividem sua distribuição entre os estados da Bahia, Distrito Federal, Goiás e Minas Gerais: C. gardneriana e C. purpurea (BA, GO), C. microphylla (BA,DF, GO), C. harleyi e C. pinheiroi (BA e MG) e C. villosa (BA, GO, MG). Os resultados são apresentados por meio de chave de identificação, descrições, distribuição geográfica, comentários e ilustrações inéditas das espécies.
\end{abstract}

Palavras-chave: Compositae, Aliança Heliantheae, taxonomia.

\begin{abstract}
Asteraceae is the largest family of angiosperms with ca. 24.000 species and 1600-1700 genera widely distributed. Calea $\mathrm{L}$. is represented in the tropical and subtropical regions by ca. 125 species. This genus is very similar to Aspilia and Wedelia, however the former presents ligulate pistilate flowers and pappus composed of free pales. The aim of this paper is to present a taxonomic survey of Calea in the state of Bahia. The analyzed specimens included material collected in the field, as well as herbarium material. The following 10 species are known to occur in Bahia: C. angusta S.F. Blake, C. candolleana (Gardner) Baker, C. gardneriana Baker, C. harleyi H. Rob., C. microphylla (Gardner) Baker, C. morii H. Rob., C. pilosa Baker, C. pinheiroi $\mathrm{H}$. Rob., C. purpurea G.M. Barroso e C. villosa Baker. The species are basically distinct by the sinflorescence arrangement (heads number and peduncle size), head radiate or discoid, receptacle (paleaceous $\times$ epaleaceous), flower numbers and pappus size. Within the genus, $C$. angusta is restricted to shrubby vegetation on dunes (Bahia and Sergipe States), C. candolleana has the widest geographical distribution (BA, TO, GO, MG and $\mathrm{PE})$, C. pilose and C. morii are known only from Bahia. The other species occur in the Bahia, Distrito Federal, Goiás and Minas Gerais states: C. gardneriana and C. purpurea (BA, GO), C. microphylla (BA, DF and GO), C. harleyi and C. pinheiroi (BA e MG) and C. villosa (BA, GO, MG). Keys, descriptions, geographic distribution, comments and illustrations are provided.
\end{abstract}

Key words: Compositae, Heliantheae Alliance, taxonomy.

\footnotetext{
'Universidade Federal da Bahia, Instituto de Biologia, Depto. Botânica, Campus Universitário de Ondina s.n., 41290-170, Salvador, BA, Brasil.

${ }^{2}$ Universidade Estadual de Feira de Santana, Depto. Ciências Biológicas, BR 116 km 03, Campus Universitário, 44031-460, Feira de Santana, BA, Brasil.

${ }^{3}$ Autor para correspondência: nadiaroque@gmail.com
} 


\section{Introdução}

Asteraceae é a maior família de angiospermas com ca. 24.000 espécies e 1.600-1.700 gêneros de distribuição cosmopolita (Funk et al. 2009). Recentes estudos moleculares têm resultado em novos arranjos sistemáticos na família e, segundo Panero \& Funk (2008), podem ser reconhecidos em Asteraceae 12 subfamílias e 43 tribos, um número muito superior aos tradicionalmente aceitos (Bremer 1994). A família é caracterizada pela inflorescência em capítulo, anteras sinânteras e cipsela geralmente com um pápus (Roque \& Bautista 2008).

A Aliança Heliantheae sensu Panero (2007a) é composta por 13 tribos e ca. 5.500 espécies ou 2025\% das espécies de Asteraceae reconhecidas (Baldwin 2009). Destas, a tribo Neurolaeneae contém cinco gêneros e ca. 150 espécies com a maioria representada nas áreas tropicais do México e América do Sul (Panero 2007b). O gênero Calea L. é o maior da tribo, com aproximadamente 125 espécies, sendo que um grande número é registrado para o nordeste da América do Sul e Brasil (Wussow et al. 1985; Pruski \& Urbatsch 1988).

Calea é facilmente confundida com espécies dos gêneros Aspilia Thours e Wedelia Jacq. No entanto, Aspilia possui flores do raio neutras, constrição no ápice das cipselas e pápus geralmente aristado; Wedelia, por sua vez, possui flores do raio pistiladas e pápus coroniforme, enquanto que em Calea as flores do raio, quando presentes, são pistiladas e o pápus é composto de páleas livres, um caráter diagnóstico para o gênero.

Segundo os estudos realizados por Baker (1884), Pruski \& Urbatsch (1988) e Pruski \& Hind (1998), Calea está representada no Brasil por ca. 85 espécies, distribuídas nos estados do Distrito Federal, Bahia, Minas Gerais, Goiás, Rio de Janeiro, São Paulo e Paraná. Contudo, Mondin \& Bringel (2010), na listagem das espécies de Calea para a Flora do Brasil, reconheceram para o gênero apenas 53 espécies amplamente distribuídas pelo Brasil.

Pelo exposto, observa-se uma grande divergência entre os resultados obtidos por meio dos estudos taxonômicos em Calea ao longo dos anos e a listagem de espécies para o Brasil recentemente publicada (Mondin \& Bringel 2010). Embora com focos distintos, esses trabalhos fornecem dados fundamentais para os estudos revisivos, cujo principal enfoque será reconhecer, reavaliar e validar todos os nomes até então aceitos e propostos para o gênero.

Sendo assim, o presente trabalho tem como objetivo o estudo taxonômico das espécies de Calea
L. no estado da Bahia, que inclui o levantamento florístico, identificação, descrição, tratamento taxonômico, ilustrações inéditas e comentários sobre as espécies, além da apresentação de chave para a identificação específica.

\section{Material e Métodos}

O levantamento, identificação e descrição das espécies de Calea para o estado da Bahia foram baseadas a partir de materiais coletados por meio de expedições botânicas cujos espécimes foram depositados principalmente no herbário ALCB, além da análise de exsicatas provenientes dos herbários ALCB, CEPEC/CEPLAC, EAC, ICN, HRB, HUEFS, SPF e US. Duplicatas dos herbários MBM, RB e UB foram analisadas no herbário US. As siglas e respectivas instituições encontram-se listadas conforme Holmgren et al. (1990).

A descrição de Calea é uma compilação de toda a variação encontrada nas espécies do gênero e literatura específica. Para a identificação dos táxons foram consultados protólogos, floras locais e regionais e, quando possível, os espécimes-tipo (identificado pelo sinal de exclamação quando analisado). As medidas vegetativas foram obtidas com auxilio de régua milimetrada e as estruturas florais foram medidas utilizando-se papel milimetrado em estereomicroscópio. As medidas de largura e diâmetro foram feitas na parte mais larga da estrutura analisada. Os espécimes foram analisados e as estruturas ilustradas sob com câmada clara acoplada ao estereomicroscópio Olympus SZH10. A morfologia das estruturas reprodutivas e vegetativas foi caracterizada com base em Radford et al. (1974) e Roque et al. (2009).

Nas descrições da lâmina foliar, os termos "ápice", "margem" e "base" foram suprimidos levando em consideração a sequência padronizada dos mesmos. O caráter - venação trinérvia ou uninérvia, comumente aplicado por Baker (1884), não foi utilizado como marcador taxonômico entre as espécies estudadas devido à sua subjetividade. Em ramos de uma mesma exsicata, observam-se folhas aparentemente trinervadas e folhas cuja nervação é duvidosa.

Os materiais examinados, adicionais e/ou selecionados seguem a ordem alfabética do município e ordem cronológica das coletas. Para as espécies C. angusta, $C$. candolleana e C. harleyi foram selecionados os materiais mais representativos em termos de variabiliade morfológica e abrangência geográfica. Optou-se por incluir materiais adicionais de outros estados para subsidiar o reconhecimento e identificações futuras. 


\section{Resultados e Discussão}

Calea L., Sp. Pl. 2: 1179. 1763. Tipo: Calea jamaicensis (L.) L.

Ervas, subarbustos, arbustos, ou raramente árvores ou lianas; algumas vezes com xilopódio e raízes tuberosas. Folhas simples, opostas, raramente alternas, verticiladas ou em roseta, subsésseis, sésseis ou pecioladas. Capítulos radiados, heterogámos ou discóides, homógamos, solitários ou em sinflorescência terminal ou axilar, paniculado-tirsóide, umbeliforme ou corimbiforme; brácteas involucrais imbricadas 2-8 séries, estriadas, subiguais ou as mais externas menores; receptáculo plano ou cônico, paleáceo ou raramente epaleáceo. Flores do raio, quando presentes, pistiladas, limbo inteiro ou trilobado, patente, amarelas, raramente alvas; flores do disco tubulosas, monoclinas, amarelas, raramente alvas ou púrpuras; anteras com apêndice do conectivo agudo, base curtamente sagitada, amarelas; ramos de estilete truncado, ápice penicelado. Cipsela cilíndrica, geralmente enegrescida pela presença de fitomelanina, 4-5 costelas, serícea, pubescente, glabra ou glabrescente, carpopódio curvado (assimétrico) e/ou decorrente, estipitado; pápus de páleas livres, raramente fundidas na base, subiguais a desiguais, margem e ápice erosas.

Segundo o levantamento realizado para o estado da Bahia, o gênero Calea conta com 10 espécies que habitam preferencialmente áreas abertas, em ambientes de caatinga, campos rupestres, cerrado, restinga ou carrasco.

\section{Chave de identificação para as espécies de Calea no estado da Bahia}

1. Capítulos homógamos, discóides; flores até 10 por capítulo.

2. Folhas 2,5-5,5 cm larg.; capítulo séssil; receptáculo paleáceo (páleas $1 \mathrm{~cm}$ compr.); páleas do pápus lanceoladas, 2-3 mm compr.

2'. Folhas 0,6-2 cm larg.; capítulo pedunculado; receptáculo epaleáceo; páleas do pápus escamiformes, até $0,5 \mathrm{~mm}$ compr.

3. Capítulo com 3 flores, brácteas involucrais e flores atropurpúreas; páleas do pápus inconspícuas (ca. 0,1 mm compr.) 9. C. purpurea

3'. Capítulo com 8-10 flores, brácteas involucrias verdes e flores amarelas; páleas do pápus ca. $0,5 \mathrm{~mm}$ compr., ovadas.

4. Lâmina foliar elíptica, serreada, atenuada; sinflorescência umbeliforme, três capítulos; carpopódio inconspícuo 4. C. harleyi

4'. Lâmina foliar ovada, crenada, truncada; sinflorecência corimbiforme, mais de três capítulos; carpopódio decorrente nas costelas

8. C. pinheiroi

1'. Capítulos heterógamos, radiados; flores $15-55$ por capítulo.

5. Capítulos com 1-2 brácteas folhosas na base, sésseis ou curtamente pedunculados (até $3 \mathrm{~cm}$ compr.); páleas do receptáculo conduplicadas, persistentes.

6. Lâmina foliar elíptica, glabrescente na face adaxial; flores ca. 15; pápus $0,2 \mathrm{~mm}$ compr.

5. C. microphylla

6'. Lâmina foliar ovada, velutina; flores ca. 30; pápus $0,5 \mathrm{~mm}$ compr.

10. C. villosa

5'. Capítulos sem brácteas folhosas na base, pedúnculo 4-23 cm compr.; páleas do receptáculo, quando presentes, planas, caducas.

7. Capítulos com páleas ausentes ou caducas, lineares; cipsela estrigosa, pápus $(0,8) 1$ $1,5(2,0) \mathrm{mm}$ larg.

8. Ramos pubescentes; lâmina foliar escabrosa a pubescente; pápus $0,8-1 \mathrm{~mm}$ compr.

9. Lâmina foliar 1,5-3(4) cm compr., oblonga a triangular, face adaxial escabrosa; receptáculo paleáceo, páleas ca. $3 \mathrm{~mm}$ compr., caducas ............ 2. 2. C. candolleana

9'. Lâmina foliar 4-8 cm compr., elíptica, face adaxial pubescente; receptáculo epaleáceo 7. C. pilosa

8'. Ramos glabros; lâmina foliar glabra a glabrescente; pápus 1,2-1,5(2,0) mm compr.

1. C. angusta

7'. Capítulos com páleas persistentes, lanceoladas; cipsela glabra e pápus até $0,2 \mathrm{~mm}$ compr. 3. C. gardneriana 
1. Calea angusta S. F. Blake, Contr. U.S. Natl. Herb. 26: 258. 1930. Galinsoga angustifolia Spreng., Neu Entd. 2: 138. 1821. Tipo: BRASIL. BAHIA, Sellow 1001 (Tipo: P; Foto do tipo: US!).

Fig. 1a-f Ageratum angustifolium Spreng., Syst. Veg. 3: 446. 1826. Tipo: BRASIL. BAHIA: Sellow 590 (Tipo: P; Foto do Tipo: US!).

= Calea angustifolia Sch. Bip. ex Baker. Fl. bras. 6: 256. 1884, nom. illeg. (non Meyeria angustifolia Gardner, Lond. Journ. Bot. 7: 417. 1848.).

Subarbustos ou arbustos, 0,3-2 m alt.; ramos decumbentes, glabros. Folhas opostas, discolores, cartáceas, aromáticas, lâmina foliar 3-6(10)×0,2-1,0 $(2,5) \mathrm{cm}$, estreito-elíptica a elíptica, aguda a obtusa, mucronulada, inteira a serrulada, levemente revoluta, decorrente, glabras ou glabrescentes, sésseis a subsésseis, pecíolo até $0,5 \mathrm{~cm}$ compr. Sinflorescência terminal, cimosa, corimbiforme; capítulos laxos, pedúnculo $8-23 \mathrm{~cm}$ compr. Capítulo radiado, heterógamo; invólucro campanulado, $1-1,5 \times 1 \mathrm{~cm}$; brácteas involucrais 3-4 séries, verdes, margem hialina, glabras, as mais externas 7-9 $\times 2-3 \mathrm{~mm}$, ovadas, arredondadas, as mais internas $0,9-1,1 \times 0,3-0,4 \mathrm{~cm}$, lanceoladas, obtusas; receptáculo cônico, paleáceo, páleas ca. $3 \mathrm{~mm} \times 0,2 \mathrm{~mm}$, lineares, planas, caducas. Flores 45-52, flores do raio 10, 1,3-1,5 cm compr., corola 8-10 mm compr. (tubo da corola $2 \mathrm{~mm}$ compr.); flores do disco $8 \mathrm{~mm}$ compr., corola ca. $4 \mathrm{~mm}$ compr. (tubo $1 \mathrm{~mm}$ compr.), amarela, anteras ca. $2 \mathrm{~mm}$ compr., estilete dilatado na base, ca. $4 \mathrm{~mm}$ compr. Cipsela 4 costada, 2,5-3 mm compr., estrigosa, levemente estipitada, carpopódio assimétrico, decorrente nas costelas; páleas do pápus 13-15, livres, subiguais, 1,2-1,5 (2,0) mm compr., elípticas.

Material selecionado: Alagoinhas, Catu, 1209'29” S 38²2'61"W, 7.X.2002, N.G. Jesus et al. 1493 (ALCB, HRB, HUEFS). Cairu, 14.IX.1993, L.M. Guedes et al. 100 (ALCB). Camaçari, 1.VII.1997, M.L. Guedes et al. 4832 (ALCB). Conde, 29.VIII.2002, N.G. Jesus et al. 1447(HRB). Entre Rios, 15.IV.2004, T. Ribeiro et al. 473 (ALCB, HUEFS). Esplanada, 3.II.2002, J.R. Pirani et al. 4960 (ALCB, SPF). Itanagra, 20.IX.2008, A.R. Prates 106 (ALCB). Jandaíra, 19.VIII.1995, G. Hatschbach et al. 63157 (CEPEC, HRB, SPF, US). Lamarão do Passé, 10.VII.1994, M.L. Guedes et al. 3335 (ALCB). Mata de São João, 18.VIII.1995, G. Hatschbach et al. 63093 (HUEFS, SPF, US). Imbassaí, 18.VI.2003, G. Hatchbach et al. 75459 (US). Salvador, 12.XII.2005, E.P. Queiroz et al. 1289(HRB).

Material adicional examinado: SERGIPE: Rod. BR-101 no trecho Estância/Aracajú, Praia de Abais, 8.X.1983, J.G. Jardim et al. 329 (ALCB, CEPEC).

Calea angusta é um nome novo proposto por Blake (1930) para a espécie Galinsoga angustifolia Spreng., uma vez que Calea angustifolia Sch.Bip.ex
Baker, que atualmente é um sinônimo de Calea multiplinervia Less., é homônimo posterior de Meyeria angustifolia Gardner.

Hind \& Miranda (2008) citaram Calea angusta para o Nordeste como restrita ao estado da Bahia, ocorrendo em ambientes de restinga e campos rupestres. Contudo, a partir da análise dos espécimes em herbários, observou-se que os limites taxonômicos entre Calea angusta, Calea candolleana e Calea pilosa eram frequentemente confundidos, gerando erros de identificação na grande parte das coleções observadas (ver outros comentários em $C$. candolleana e C. pilosa).

Sendo assim, esse trabalho reconhece Calea angusta como uma espécie restrita a ambientes de restinga e dunas no litoral da Bahia e Sergipe. A espécie pode ser reconhecida pelos ramos gabros e folhas glabras a glabrescentes, lâmina estreito-elíptica a elíptica, aromáticas e pela presença do maior pápus (páleas 1,2-1,5 (2,0) mm compr.) entre as espécies de Calea da Bahia (Fig. 1a-f). O material coletado no Município Mata de São João (G. Hatschbach et al. 63093), em região de restinga arbórea, apresentou as folhas excepcionalmente largas (ca. $3 \mathrm{~cm}$ larg.).

2. Calea candolleana (Gardner) Baker. Fl. bras. 6(3): 256. 1884. Meyeria candolleana Gardner. London J. Bot. 7: 414. 1848. Síntipos: BRASIL. PERNAMBUCO (?): Serra de Batalha, 1841, G. Gardner 2903 (Síntipo: K; Foto do tipo: HUEFS! US!) e GOIÁS, "in similar situations near San Domingos", V.1840, G. Gardner 4242 (tipo: K, US!).

Fig. 1g-k

Arbusto ereto a decumbente até $2 \mathrm{~m}$ alt., muito ramificado; ramos pubescentes. Folhas opostas, discolores, cartáceas, lâmina foliar 1,5-3(4) ×1-1,5(2) $\mathrm{cm}$, oblonga ou triangular, obtusa a aguda, serreada, revoluta, decorrente, face adaxial escabrosa, face abaxial híspida a pubescente com tricomas glandulares capitados, sésseis a subsésseis, pecíolo até $4 \mathrm{~mm}$ compr. Sinflorescência terminal, cimosa, corimbiforme; capítulos laxos, pedúnculo 4-16 cm compr. Capítulo radiado, heterógamo; invólucro campanulado, 1,0 $1,5 \times 1,0 \mathrm{~cm}$; brácteas involucrais 3-4 séries, verdes, margem hialina, glabras, as mais externas $0,5-1,0 \times$ $0,3-0,8 \mathrm{~cm}$, ovadas, arredondadas, as mais internas 0,6-1×0,4 cm, elípticas, obtusas; receptáculo cônico, paleáceo, páleas 4-10 ×0,2 $\mathrm{mm}$, lineares, planas, caducas. Flores ca. 55 , as do raio $10,1-1,5 \mathrm{~cm}$ compr., corola $1,1 \mathrm{~mm}$ compr. (tubo $1,5-2 \mathrm{~mm}$ compr.); flores do disco 7-8 mm compr., corola 3,5-4 mm compr. (tubo $0,8-1 \mathrm{~mm}$ compr.), amarela, anteras ca. $2 \mathrm{~mm}$ compr., estilete dilatado na base, ca. 3,5 mm compr. 


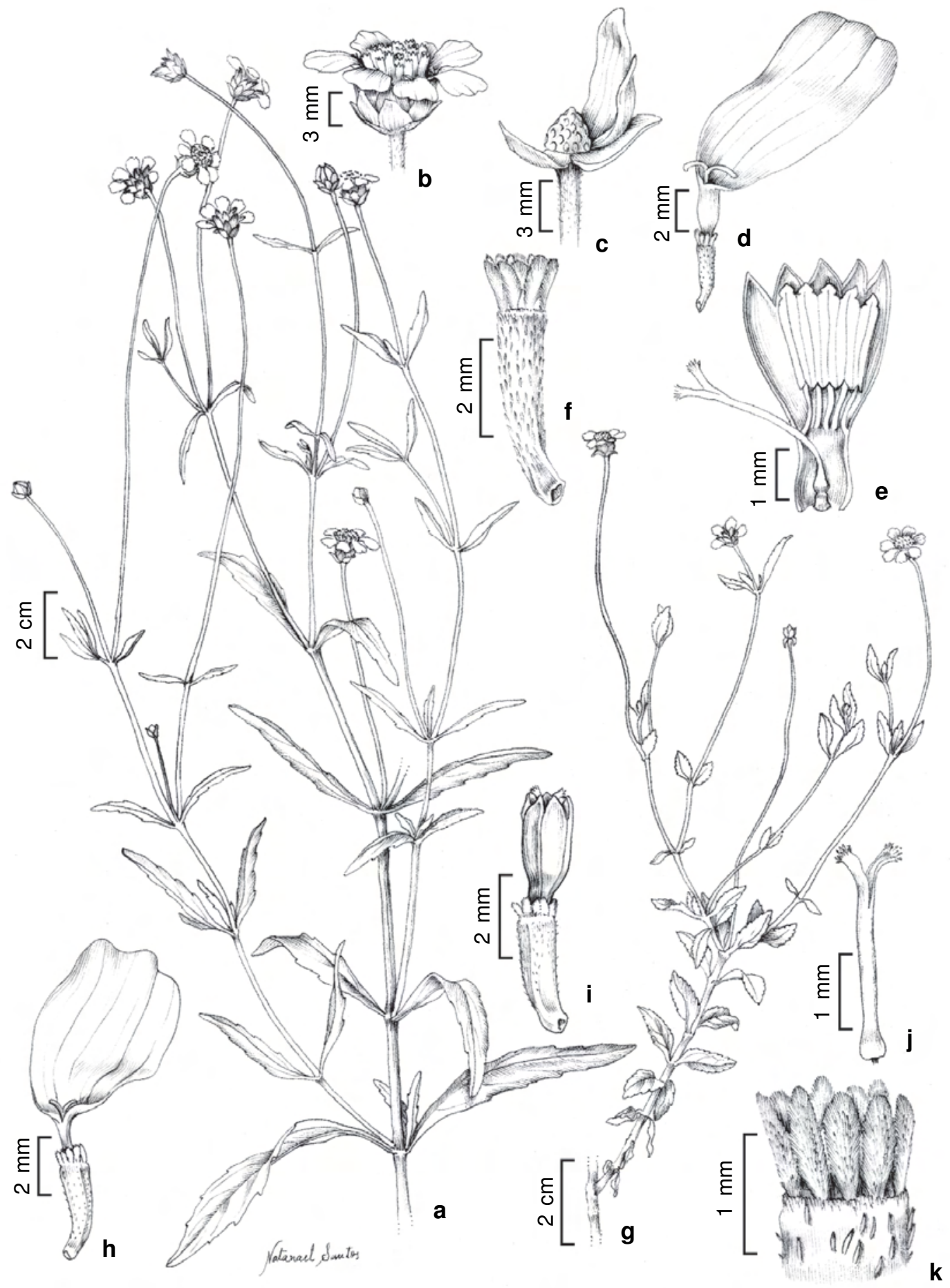

Figura 1 - a-f. Calea angusta S.F. Blake - a. ramo florido; b. capítulo radiado; c. receptáculo cônico; d. flor do raio; e. flor do disco em corte longitudinal evidenciando os estames e estilete; f. cipsela (Guedes et al. 4832). g-k. Calea candolleana (Gardner) Baker - g. ramo florido; h. flor do raio; i. flor do disco; j. estilete; k. pápus de páleas (Harley et al. 25717). Figure 1 - a-f. Calea angusta S.F. Blake - a. flowering shoot; b. radiate head; c. conic receptacle; d. ray floret e. disc floret showing the stamen and style; f. cypselae (Guedes et al. 4832). g-k. Calea candolleana (Gardner) Baker - g. flowering shoot; h. ray floret; i. disc flower; j. style; k. pappus of pales (Harley et al. 25717). 
Cipsela 4-costada, 2,5-3 mm compr., estrigosa, carpopódio assimétrico, decorrente nas costelas; páleas do pápus 12-13, livres, subiguais, ca. $1 \mathrm{~mm}$ compr., elípticas.

Material selecionado: Abaíra, 19.XII.1991, R.M. Harley \& V.C. Souza H 50103 (HUEFS, SPF, US). Andaraí, $12^{\circ} 15 \mathrm{~S}$, $41^{\circ} 18 \mathrm{~W}, 24$. XI.2001, E.C. Oliveira \& V.C. Carvalho 4 (HUEFS). Barra da Estiva, 16.II.1997, B. Stannard et al. PCD 5749 (ALCB, CEPEC, HRB, HUEFS). Caetité, 28.IV.2008, M.L. Guedes et al. 14.276(ALCB). Castro Alves, 18.V.1999, V.C. Souza et al. 22627 (HUEFS, SPF). Delfino, 5.III.1974, R.M. Harley 16791 (CEPEC). Ibicoara, 13.X.2007,

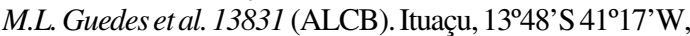
19.VII.1981, A.M. Giulietti et al. CFCR 1222 (ALCB, US). Jacobina, 11¹2'24”S, 40²8'55”'W, 7.IV.2001, N.G. Jesus et al. 1303 (CEPEC, HRB, HUEFS). Lençóis, 31.VIII.1994, $R$. Orlandi et al. PCD 651 (ALCB, CEPEC, US). Morro do Chapéu, 11\%40'22'S 4100'39'W, 9.XII.2006, M.L. Guedes et al. 12971 (ALCB, HRB). Mucugê, 1259'18”S, 41'20'27''W, 13.III.2004, N. Roque et al. 1092 (ALCB, HRB). Palmeiras, 28.VIII.2008, P.D. Carvalho \& S.C. Ferreira 416 (HUEFS). Paraguaçu, 139'S, 41 ${ }^{\circ} 7$ 'W, 13.IV.2001, L.J. Alves et al. 65 (ALCB). Piatã, 25.III.2005, M.L. Guedes et al. 11.888 (ALCB, CEPEC). Pindobaçu, 1041'35" S 40²2'45” W, 10.IV.2001, T. Ribeiro et al. 219 (ALCB, HRB, HUEFS). Rio de Contas, 28.X.1988, R.M. Harley et al. 25717 (CEPEC, HUEFS, SPF, US). Santa Terezinha, 16.V.1984,L.R. Noblick et al. 3236 (CEPEC, HUEFS, US). Sento Sé, 2.IV.2002, E.R. Souza et al. 142 (ALCB, HUEFS). Umburanas, 10²2'S, 41¹9'W, 10.IV.1999, L.P. de Queiroz et al. 5220 (HUEFS). Utinga, 12³'10'S, 41 7'33'W, 10.IX.1999, R.P. Oliveira et al. 204 (HUEFS).

Material adicional examinado: MINAS GERAIS. Várzea da Palma, 12.III.1995, G. Hatchsbach et al. 61781 (US).

Calea candolleana ocorre preferencialmente em áreas de campos rupestres, cerrado, borda de mata ciliar e beira de estrada. A espécie apresenta ampla distribuição geográfica, com registro para os estados de Tocantins, Goiás, Minas Gerais, Bahia e Pernambuco (Mondin \& Bringel 2010). Por outro lado, Hind \& Miranda (2008) citam C. candolleana com distribuição no Nordeste restrita ao estado da Bahia. A citação de Calea candolleana para Pernambuco se dá através da etiqueta do materialtipo e que, semelhante a $C$. mycrophylla, pode estar equivocada. Estudos sobre o percurso realizado por Gardner no Brasil podem elucidar com exatidão as localidades-tipo de várias espécies por ele descritas.

Calea candolleana pode ser confundida com C. angusta e C. pilosa, mas diferencia-se da primeira pelo tipo de hábitat (campos rupestres e cerrado vs. restinga), enquanto $C$. angusta apresenta ramos glabros ( $v s$. pubescentes), lâmina estreito-elíptica a elíptica ( $v s$. oblonga a triangular), glabras a glabrescentes ( $v s$. híspida a pubescente) e pápus maior. Calea candolleana diferencia-se de C. pilosa pela formato da lâmina (oblonga vs. elíptica), tipo de indumento (face adaxial escabrosa $v s$. pubescente) e presença de páleas no receptáculo ( $v s$. epaleáceo) (Fig. 1g-k).

Os espécimes de $C$. candolleana coletados nos Municípios de Morro do Chapéu e Jacobina, Bahia, são particularmente característicos pelas folhas triangulares, menores $(1,5-3,5 \times 0,4-0,7)$, fortemente revolutas e sésseis. Devido à ampla variação foliar encontrada ao longo dos espécimes estudados, optou-se, então, pela ampliação dos limites específicos.

A partir da análise dos protólogos e dos materiais-tipo das espécies de Calea citadas para a Bahia, observou-se que Calea bahiensis (Mattf.) $\mathrm{H}$. Rob. e C. angusta são reconhecidas pelos mesmos caracteres diagnósticos, o que sugere que a primeira seja sinonimizada em futuro trabalho revisivo no gênero.

3. Calea gardneriana Baker, Fl. bras. 6 (3): 255. 1884. Meyeria angustifolia Gardner, London J. Bot. 7: 414.1848 (nom. illeg.) Tipo: BRASIL. GOIÁS, Serra da Natividade, IV.1840, G. Gardner 3282 (Holótipo: K; Foto: US!). Fig. 2a-d

Arbustos até 1,5 m alt.; ramos glabrescentes. Folhas opostas, discolores, cartáceas, lâmina foliar 4-8 × 0,2-0,5 cm, linear, aguda, inteira, atenuada, estrigosas, sésseis. Sinflorescência terminal, cimosa, corimbiforme; capítulos laxos, pedúnculo 4-11 cm compr. Capítulo radiado, heterógamo; invólucro campanulado, 1-1,5×1-1,3 cm; brácteas involucrais 3-4 séries, verdes, margem hialina, glabras, as mais externas 2-3 × 1-2 mm, ovadas, arredondadas, as mais internas 3-10 × 2-4 mm, elípticas, obtusas; receptáculo cônico, paleáceo, páleas $7-8 \times 1 \mathrm{~mm}$, lanceoladas, aristadas, planas, persistentes. Flores ca. 40, flores do raio ca. 10, 1,5-1,9 cm compr., corola 1,0-1,3 cm compr. (tubo $2 \mathrm{~mm}$ compr.), flores do disco $1,0 \mathrm{~cm}$ compr., corola ca. $5 \mathrm{~mm}$ compr. (tubo $1 \mathrm{~mm}$ compr.), amarela, anteras ca. $3 \mathrm{~mm}$ compr., estilete dilatado na base, ca. $4 \mathrm{~mm}$ compr. Cipsela 4-costada, 5-6 mm compr., cilíndrica, glabra, carpopódio assimétrico e inconspícuo; páleas do pápus 12-15, livres, subiguais, ca. 0,5 mm compr., elípticas.

Material examinado: Gentio do Ouro, $11^{\circ} 2$ ' $18^{\prime}$ 'S 4242'48'W, 24.VI.1996, M.L. Guedes et al. PCD 3043 (ALCB, CEPEC, HRB, HUEFS, SPF). Xique-Xique, 11²'S e 4242'W, II.1977, R. M. Harley 19078 (CEPEC). Material adicional examinado: GOIÁS, Serra D'ourada, Pohl 445 (US).

Calea gardneriana foi um nome novo proposto por Baker (1884) para Meyeria angustifolia Gardner 


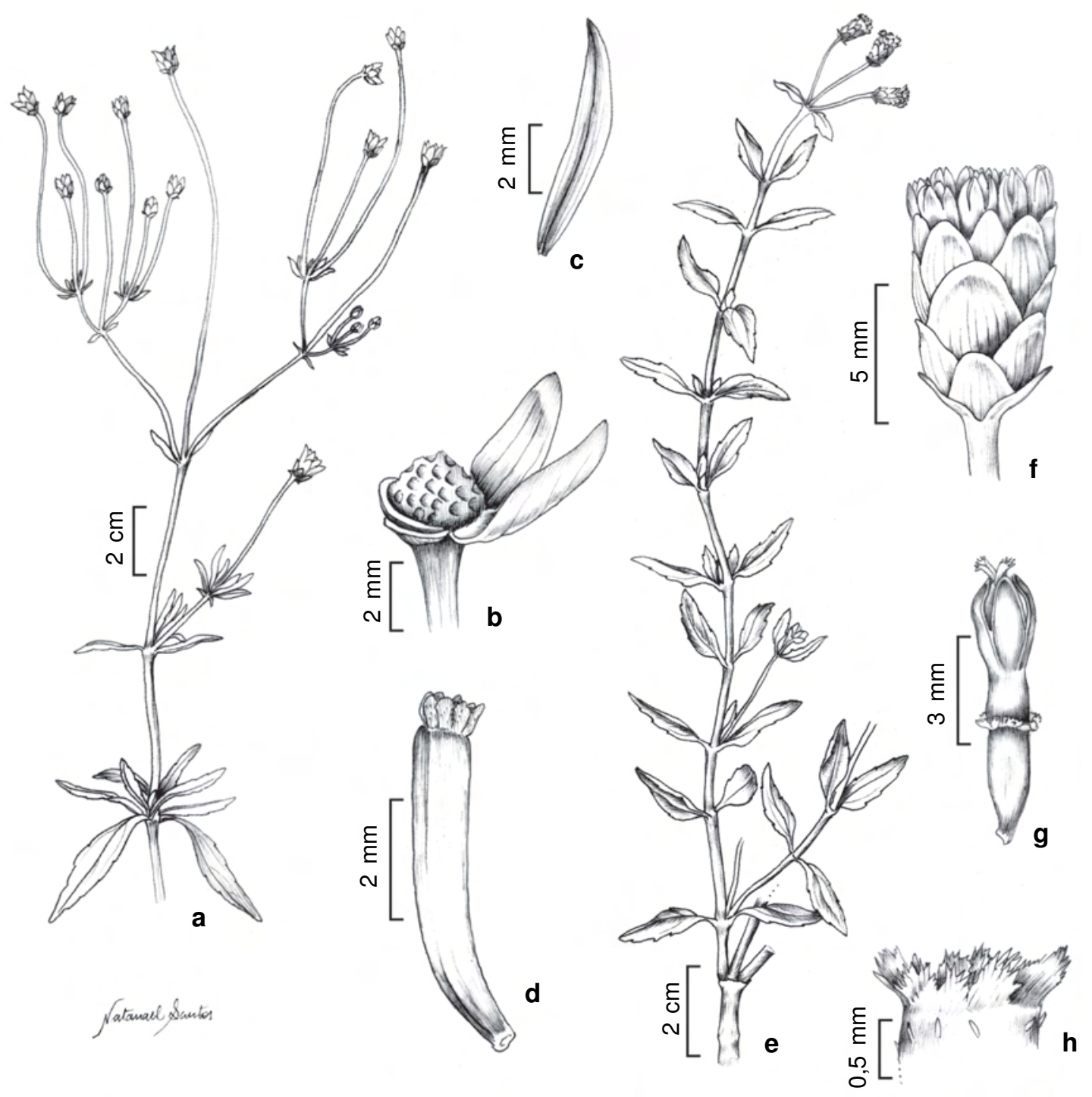

Figura 2 - a-d. Calea gardneriana Baker - a. ápice do ramo florido; b. receptáculo cônico; c. pálea do receptáculo; d. cipsela (Guedes et al. PCD 3043). e-h. Calea harleyi H. Rob. - e. ramo florido; f. capítulo discóide; g. flor do disco; h. pápus de páleas (Roque et al. 651).

Figure 2 - a-d. Calea gardneriana Baker - a. flowering shoot apex; b. conic receptacle; c. receptacle pale; d. cypselae (Guedes et al. PCD 3043). e-h. Calea harleyi H. Rob. - e. s flowering shoot; f. discoid head; g. disc floret; h. pappus of pales (Roque et al. 651).

que era um homônimo posterior para Ageratum angustifolium Spreng.

Seguno Hind \& Miranda (2008), os espécimes PCD 3043 e Harley 19078 foram identificados como Calea elongata (Gardner) Baker e, possivelmente, o mesmo conceito taxonômico foi seguido por Mondin \& Bringel (2010). Contudo, após a análise do síntipo "Pohl 445" de Calea gardneriana (Gardner) Baker, concluiu-se que este espécime mantinha os mesmos limites taxonômicos que os espécimes provenientes da Bahia. Uma vez que nenhum espécime-tipo de Calea elongata foi analisado e, segundo Baker (1884), a espécie é restrita a Goiás, optou-se pela identificação destes espécimes como Calea gardneriana.

Calea gardneriana ocorre em áreas de cerrado e campos rupestres nos estados de Bahia e Goiás. Dentre as espécies estudadas, $C$. gardneriana é a única com lâmina foliar linear $(4-8 \times 0,3-0,4 \mathrm{~cm}) \mathrm{e}$ cipsela glabra com pápus inconspícuo (ca. 0,2 mm 
compr.) (Fig. 2a-d). Calea gardneriana, assim como C. candolleana, C. pilosa e C. angusta, apresentam capítulos sem brácteas folhosas na base e pedunculados.

4. Calea harleyi H. Rob., Phytologia 44(4): 272. 1979. Tipo: BRASIL. BAHIA. Barra da Estiva on Ibicoara Road. $41^{\circ} 18^{\prime} \mathrm{W}, 13^{\circ} 35^{\prime}$ 'S, Alt. ca. $1,100 \mathrm{~m}$, 29.I.1974, R.M. Harley 15586 (Holótipo: US!, Isótipo: CEPEC!)

Fig. 2e-h

Arbustos 20-70 cm alt.; prostrados ou cespitosos, glabros a levemente pubescentes. Folhas opostas, discolores, cartáceas, lâmina foliar 2-4,5×0,6$1,2 \mathrm{~cm}$, elíptica, aguda a obtusa, serreada, levemente revoluta, atenuada, estrigosas, glabrescentes, subsésseis, pecíolo 2-8 mm compr. Sinflorescência terminal, cimosa, umbeliforme, tricapitada; capítulos laxos, pedúnculo 0,6-1,5 cm compr. Capítulo discóide, homógamo; invólucro cilíndrico, 7-10× 4-7 mm; brácteas involucrais 4-5 séries, verdes, margem hialina, glabras, as mais externas $5 \times 1,5-2 \mathrm{~mm}$, ovadas, arredondadas, as mais internas $6 \times 0,5 \mathrm{~mm}$, lineares a lanceoladas, obtusas; receptáculo cônico, glabro. Flores 8-10, ca. 6 mm compr., corola 3-4 mm (tubo 0,8$1 \mathrm{~mm}$ compr.), amarela, anteras ca. $2 \mathrm{~mm}$ compr., estilete dilatado na base, 3,5-4mm compr. Cipsela 4-costada, ca. $3 \mathrm{~mm}$ compr., levemente estrigoso nas costelas, glabrescente, carpopódio assimétrico, inconspícuo; páleas do pápus ca. 12 , livres, subiguais, ca. $0,5 \mathrm{~mm}$ compr., ovadas.

Material selecionado: Abaíra, 2.II.1992, J.R. Pirani et al. H 51467 (CEPEC, HUEFS, SPF, US). Água Quente, 11.XII.1988, R.M. Harley et al. 27206 (HUEFS, SPF, US). Barra da Estiva, 22.III.1980, Harley et al. 20764 (CEPEC). Brejo de Cima, 15.XII.1984, B. Stannard et al. CFCR 6943 (SPF, US). Caetité, 8.III.1994, V.C. Souza et al. 5360(ALCB,

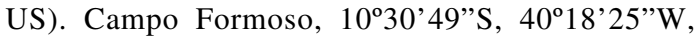
14.VIII.1999, E. Miranda-Silva et. al. 199 (ALCB, HUEFS). Ibicoara (Ibiquara), $13^{\circ} 25^{\prime} \mathrm{S}, 41^{\circ} 18^{\prime} \mathrm{W}, 20 . \mathrm{XI} .1988$, R.M. Harley et al. 26976 (ALCB, CEPEC, SPF, US). Igaporã, 10.III.1998, G. Hatschbach et al. 67589 (US). Lençóis, 25.IV.1979, L.R. Noblick 1232 (ALCB). Mucugê, 1.V.2003, N. Roque et al. 651 (ALCB, CEPEC, SPF). Piatã, 10.X.2009, N. Roque et al. 2274 (ALCB). Rio de Contas, 18.III.1998, G. Hatschbach et al. 67894 (ALCB, US). Seabra, 20.III.1980, G.C. Pinto 122 (HRB). Sebastião Laranjeiras, 14³4'S, 4244'W, 17.IX.1980, S.B. da Silva 135 (CEPEC, HRB).

Material adicional examinado: MINAS GERAIS, Bocaiúva, BR-367, 20.XI.1997, G. Hatschbach et al. 67306 (US). Botumirim, 15.II.2003, F. França et al. 4410 (HUEFS). Monte Azul, 18.IV.1996, G. Hatschbach et al. 65058 (US).

Calea harleyi, até então conhecida apenas para o estado da Bahia (Hind \& Miranda 2008; Mondin \& Bringel 2010), agora tem sua distribuição geográfica estendida para Minas Gerais. Ocorre em áreas de cerrado de altitude em afloramento rochoso, carrasco, caatinga, campos gerais, beira de riacho, campos rupestres e em vegetação antrópica. Nestes ambientes ocorre em solo arenoso e afloramento rochoso e apresenta xilopódio evidente.

Calea harleyi é característica pelos capítulos discóides, homógamos e diferencia-se das demais espécies com capítulos discóides ( $C$. morii, C.pinheiroi e C. purpurea) pelas folhas elípticas, sinflorescência em umbela tricapitada e 8-10 flores por capítulo (Fig. 2e-h).

5. Calea microphylla (Gardner) Baker, Fl. bras. 6 (3): 260. 1884. Meyeria microphylla Gardner. Lond. Journ. Bot. 7: 413.1848. Tipo: BRASIL. BAHIA: "in udis ad ripas Rio Preto", IX.1839, G. Gardner 2904 (Holótipo: K; Foto do Tipo: US!). $\quad$ Fig. 3a-i

Arbusto até $50 \mathrm{~cm}$ alt.; ramos pubescentes. Folhas opostas, discolores, membranáceas, lâmina foliar $0,5-1,0(1,5) \times 0,3-0,8 \mathrm{~cm}$, elíptica, aguda a obtusa, serreada, decorrente, face adaxial glabrescente, face abaxial pubescente, subsésseis, pecíolo 1-3 mm compr. Sinflorescência terminal, cimosa, umbeliforme; capítulos laxos, pedúnculos 1-3cm compr. Capítulo radiado, heterógamo, 1-2 séries brácteas folhosas na base, ovadas a oblongas, 4-5 $\times 2-3 \mathrm{~mm}$, pubescentes; invólucro campanulado, $1 \times 0,5-1 \mathrm{~cm}$; brácteas involucrais 3-4 séries, verdes, margem hialina, as mais externas $2-4 \times 1-2 \mathrm{~mm}$, ovadas, arredondadas, ápice seríceo, glabrescentes, as mais internas 5-8 $\times 2-3 \mathrm{~mm}$, lineares a elípticas, obtusas, glabras; receptáculo levemente côncavo, paleáceo, páleas 5-6×1 mm, lanceoladas, aristadas, conduplicadas, persistentes. Flores ca. 15 , as do raio 5, 1,0-,3 cm compr., corola 6-7 mm compr. (tubo 1,5 $\mathrm{mm}$ compr.); flores do disco 8-9 mm compr., corola 3,5-4 mm compr. (tubo 1-1,5 mm compr.), amarela, anteras ca. $2,5 \mathrm{~mm}$ compr., estilete dilatado na base, ca. 4mm compr. Cipsela 4-costada, 3-4 mm compr., glabrescente, carpopódio assimétrico, decorrente nas costelas; páleas do pápus ca. 16, livres, subiguais, $0,3-0,5 \mathrm{~mm}$ compr., elípticas.

Material examinado: Barreiras, $11^{\circ} 38 \mathrm{~S}, 45^{\circ} 15 \mathrm{~W}$, 5.IV.1978, C.A. Miranda 255 (HRB). Correntina, 1320'S, 44³8'W, III.1991, L.G. Viollati et al. 188 (ALCB, SPF). Formosa do Rio Preto, 1053'23', 45¹4'46', 28.III.2000, R.M. Harley et al. 53733 (ALCB, CEPEC, HRB, HUEFS). Riachão das Neves, 6.IV.2005, J.G. Carvalho-Sobrinho et al. 417(ALCB). São Desidério, 13.IV.2005, L.P. de Queiroz et al. 10264 (HUEFS).

Material adicional examinado: DISTRITO FEDERAL: 4.IV.1983, J.H. Kirkbride Jr 5147 (US). GOIÁS: Chapada das Mangabeiras, 30.II.1978, C.A. Miranda 192 (HRB). 


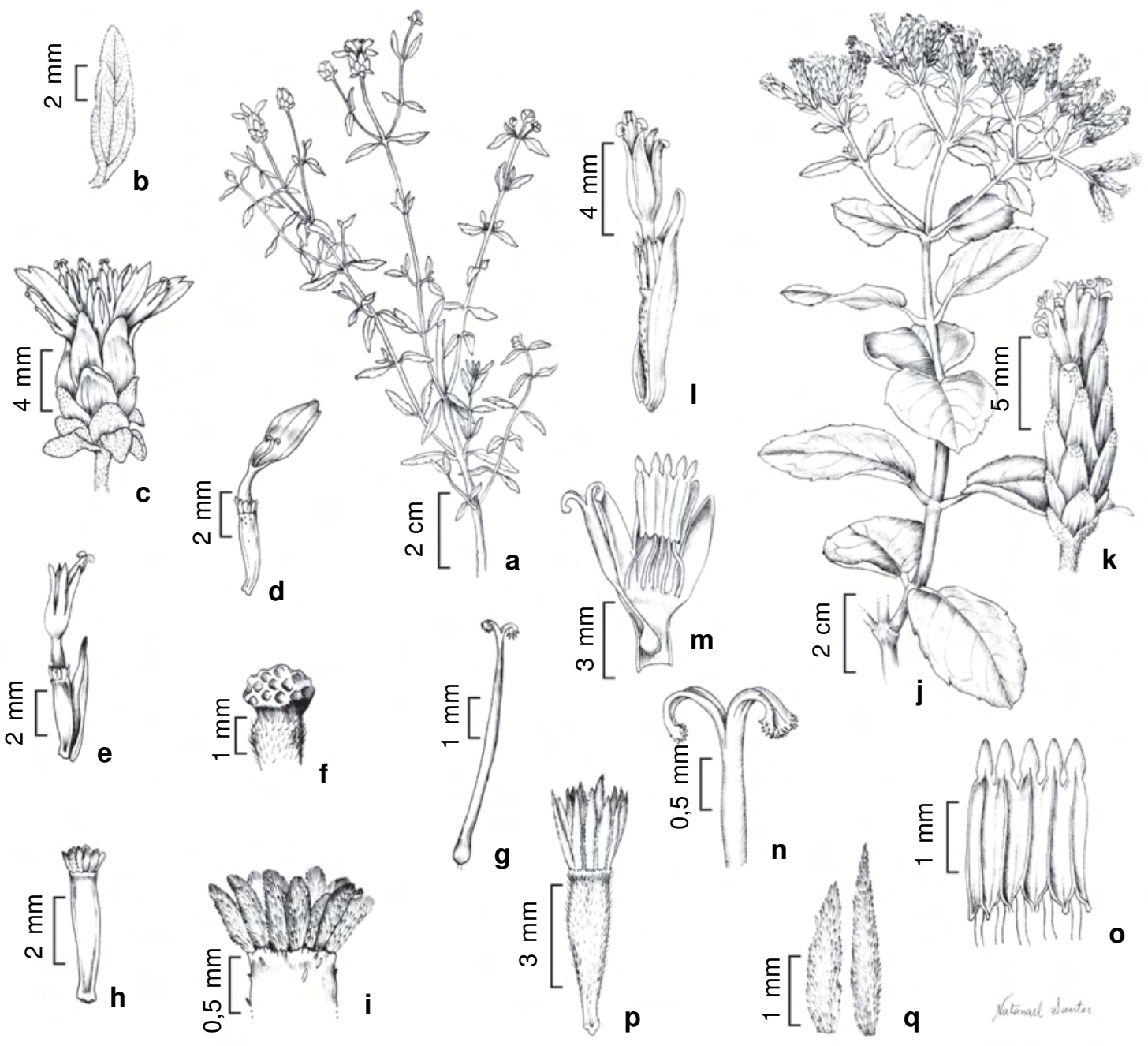

Figura 3 - a-i. Calea microphylla (Gardner) Baker - a. ramo florido; b. folha (face adaxial); c. capítulo radiado; d. flor do raio; e. flor do disco e pálea do receptáculo; f. receptáculo; g. estilete; h. cipsela; i. pápus de páleas (Harley et al. 53733).j-q. Calea morii H. Rob. - j. ramo florido; k. capítulo discóide; 1. flor do disco e pálea do receptáculo; m. flor em corte longitudinal evidenciando estames e estilete; n. ramos do estilete; o. estames com anteras sinânteras; p. cipsela; q. brácteas involucrais (Ganev 3579).

Figure 3 - a-i. Calea microphylla (Gardner) Baker - a. flowering shoot; b. daxial leaf; c. radiate head; d. ray floret; e. disc floret and receptacle pale; f. receptacle; g. style; h. cypselae; i. pappus of pales (Harley et al. 53733). j-q. Calea morii H. Rob. - j. flowering shoot; k. discoid head; 1 . disc floret and receptacle pale; m. floret showing stamen and style; $n$. style branches; o. stamens with synantherous anthers; p. cypselae; q. involucre bracts (Ganev 3579).

Cristalina, 10.II.1990, G. Hatschbach et al. 53778(HRB). São Domingos, 14.IV.2005, E.B. de Souza et al. 1172 (HUEFS).

Baker (1884) cita o material-tipo de Calea microphylla para Pernambuco (Habitat in prov. Pernambuco, in udis ad ripas Rio Preto: Gardner n. 2904!), contudo, acredita-se que o Rio Preto citado refere-se, na verdade, ao Município Formosa do Rio Preto, no estado da Bahia (ver comentários em $C$. candolleana). As listagens preliminares de
Calea para o Nordeste (Hind \& Miranda 2008) e para o Brasil (Mondin \& Bringel 2010) corroboram que a espécie não estende sua distribuição para o estado de Pernambuco.

Calea microphylla ocorre em áreas de cerrado, cerradão, campo rupestre e afloramento rochoso nos estados da Bahia, Distrito Federal e Goiás.

Calea microphylla, assim como C. villosa, são características pelas folhas diminutas $(0,5-2,0 \times 0,3-$ 
1,3 cm), capítulos com 1-2 série de brácteas folhosas na base, curto-pedunculados (1-3 cm compr.) e páleas do receptáculo conduplicadas. Porém, C. microphylla se caracteriza pela lâmina foliar elíptica, glabrescente na face adaxial, número reduzido de flores (ca. 15) e pápus ca. $0,2 \mathrm{~mm}$ compr. Diferentemente, $C$. villosa apresenta indumento velutino persistente nas folhas e ramos, lâmina foliar ovada, maior número de flores por capítulo (ca. 30) e páleas do pápus maiores, ca. 0,5 mm compr.(Fig. 3a-i).

Segundo Mondin \& Bringel (2010), Calea teucriifolia (Gardner) Bakeré uma espécie citada para a Bahia, além dos estados de Mato Grosso, Goiás, Distrito Federal e Minas Gerais. Contudo, ao analisar materiais provenientes da região sudeste e os protólogos e fototipos de C. microphylla e C. teucriifolia, observou-se a clara sobreposição entre os caracteres diagnósticos dessas espécies. Acredita-se que estudos revisivos no gênero possam discutir objetivamente os limites taxonômicos entre essas espécies.

6. Calea morii H. Rob., Phytologia 44(7): 437. 1979. Tipo: BRASIL. BAHIA: Rio de Contas, base do Pico das Almas, 22.VII.1979, King, R.M., S.A. Mori, T.S. Santos \& J.L. Hage 8097 (Isótipo: US!, CEPEC!; Foto do tipo: HUEFS!). $\quad$ Fig. 3j-q

Arbustos 1,2-2,5 m alt.; ramos pubescentes. Folhas opostas, discolores, cartáceas, lâmina foliar 3,5-9,5 × 2,5-5,5 cm, largamente elíptica a ovada, obtusa, denticulada, arredondada, face adaxial glabrescente, face abaxial vilosa, peciolada, pecíolo 0,5-1 cm compr. Sinflorescência terminal, cimosa, corimbiforme; capítulos congestos, sésseis a subsésseis, pedúnculo 3-10 mm compr. Capítulo discóide, homógamo; invólucro cilíndrico $2,5 \times 0,5$ $\mathrm{cm}$; brácteas involucrais 4-6 séries, verdes, margem hialina, ápice viloso, glabrescentes, as mais externas $2-3,5 \times 1,5-2 \mathrm{~mm}$, ovadas, obtusas, as mais internas 9-12 $\times 2-3 \mathrm{~mm}$, lanceoladas a lineares, obtusas; receptáculo cônico, paleáceo; páleas ca. 1 cm compr., lanceoladas, conduplicadas, persistentes. Flores 5, ca. $1,2 \mathrm{~cm}$ compr., corola $6-8 \mathrm{~mm}$ compr. (tubo $2 \mathrm{~mm}$ compr.), amarela, anteras $2,5-3 \mathrm{~mm}$ compr., estilete dilatado na base, ca. $5 \mathrm{~mm}$ compr. Cipsela 4-costada, 3,5-4 mm compr., estipitada, serícea, carpopódio decorrente nas costelas; páleas do pápus 15-20, livrs, subiguais, 2-3 mm compr., lanceoladas.

Material examinado: Abaíra, $13^{\circ} 17^{\prime} \mathrm{S}, 41^{\circ} 53^{\prime} \mathrm{W}$, 18.VII.1994, W. Ganev 3579 (ALCB, HUEFS, SPF, US). Ibicoara, 5.IX.1997, H.P. Bautista et al. 2256 (HRB). Lençóis, 25.X.1996, D.J.N. Hind \& L. Funch PCD 3786 (ALCB, CEPEC, HUEFS, SPF). Mucugê, 29.X.2005, J.G. Carvalho-Sobrinho et al. 666 (CEPEC, HUEFS).
Palmeiras, $12^{\circ} 25^{\prime} 27^{\prime} \mathrm{S}, 41^{\circ} 28^{\prime} 41^{\prime \prime} \mathrm{W}, 1 . \mathrm{V} .2003$, N. Roque

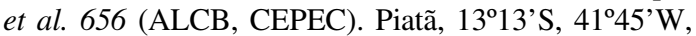
5.IX.1996, R.M. Harley et. al 28282 (CEPEC, HUEFS, SPF). Ponto Novo, 1051', 4008', 21.IX.2000, D.S. Almeida 67 (ALCB). Rio de Contas, 1352'S, 42¹9' W, 25.VIII.1993, W. Ganev 2132 (HUEFS, US).

Urbatsch et al. (1986) considerou Calea morii H.Rob., espécie até então conhecida apenas do estado da Bahia, como sinônimo de Calea fruticosa (Gardner) Urbatsch, Zlotsky \& Pruski, uma espécie cuja distribuição foi ampliada para o Distrito Federal, Bahia, Goiás e Minas Gerais, e assim reconhecida por Mondin \& Bringel (2010) na lista das espécies do gênero para o Brasil. Contudo, Pruski \& Urbatsch (1988) reapresentaram as espécies de Calea sect. Lemmatium e revalidaram Calea morii da sinonímia de Calea fruticosa, citando a espécie como endêmica da Bahia.

Nesse trabalho, Calea morii é reconhecida por ocorrer em vegetação de caatinga, campo rupestre, cerrado, cerrado de altitude e carrasco no estado da Bahia.

Calea morii, assim como C. harleyi, C. pinheiroi e $C$. purpurea, são as únicas espécies reconhecidas para a Bahia com capítulso discóides (Fig. 3j-q). Contudo, Calea morii é facilmente distinta por reter várias características diagnósticas, entre eles, as folhas largamente elípticas ou ovadas, inflorescência corimbosa, pluricéfala, capítulo cilíndrico, receptáculo paleáceo e páleas do pápus lanceoladas, conduplicadas, conspícuas (2-3 mm compr.) e persistentes.

7. Calea pilosa Baker, Fl. bras. 6(3): 257. 1884. Tipo: BRASIL. In campis Brasiliae, Pohl 326 (Tipo: K; Foto do Tipo: US!)

Fig. 4a-i

Subarbusto ereto, ca. $50 \mathrm{~cm}$ alt.; ramos prostrados, pubescentes. Folhas opostas, discolores, membranáceas, lâmina foliar 4,0-8,0 $\times 0,8-1,5 \mathrm{~cm}$, elíptica, obtusa, serrulada a serreada, plana a levemente revoluta, decorrente, pubescentes, sésseis a subsésseis, pecíolo até $5 \mathrm{~mm}$ compr. Sinflorescência terminal, cimosa, corimbiforme; capítulos laxos, pedúnculo 5-12 cm compr. Capítulo radiado, heterógamo; invólucro campanulado, 1-1,5 × 1$1,5 \mathrm{~cm}$; brácteas involucrais 4 séries, verdes, margem hialina, glabrescentes, as mais externas 4 $6 \times 2-3 \mathrm{~mm}$, ovadas, arredondadas, as mais internas 8-10×3-4 mm, oblongas, arredondadas; receptáculo cônico, epaleáceo. Flores 45-50, as do raio ca. 10, 1,5$2,0 \mathrm{~cm}$ compr., corola $1-1,2 \mathrm{~mm}$ compr. (tubo $2 \mathrm{~mm}$ compr.); flores do disco 8-9 mm compr., corola 3,54,5 mm compr. (tubo $1 \mathrm{~mm}$ compr.), amarela, anteras $2 \mathrm{~mm}$ compr., estilete dilatado na base, $4 \mathrm{~mm}$ compr. 


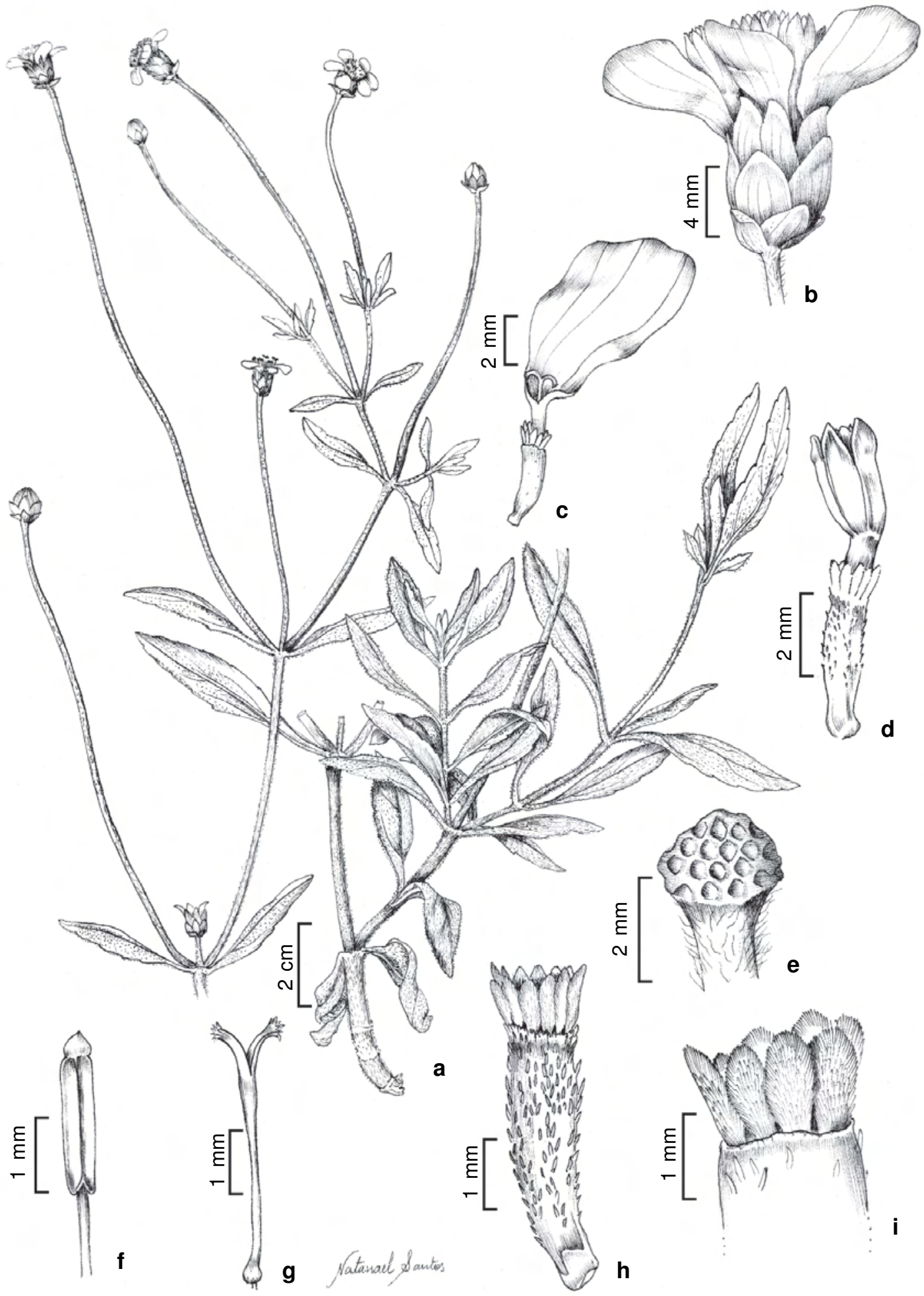

Figura 4 - Calea pilosa Baker - a. ramo; b. capítulo radiado; c. flor do raio; d. flor do disco; e. receptáculo cônico; f. estame; g. estilete; h. cipsela; i. pápus de páleas (Sant'ana et al. 118).

Figure 4 - Calea pilosa Baker - a. flowering shoot; b. radiate head; c. ray floret; d. disc floret; e; conic receptacle; f. stamen; g. style; h. cypselae; i. pappus of pales (Sant'ana et al. 118). 
Cipsela 4 costelas, 3-3,5 mm compr., densamente setulífera a esparsamente estrigosa, carpopódio assimétrico e decorrente nas costelas; páleas do pápus 13-15, livres, subiguais, $0,8-1 \mathrm{~mm}$ compr., elípticas. Material examinado: Canavieiras, M.L. Guedes et al. 93 (ALCB). Itacaré, 15.VII.1995, J.G. Jardim et al. 644 (ALCB, CEPEC, US). Nova Viçosa, 9.IV.1984, G. Hatschbach et al. 47762 (CEPEC, US). Porto Seguro, $16^{\circ} 20^{\prime}$ S, 39²'W, 27.VII.1984, G.L. Webster 25071 (CEPEC). Santa Cruz de Cabrália, 13.XII.1991, S.C. de Sant'ana et al. 118 (HRB, US).

Segundo Hind \& Miranda (2008), Calea pilosa tem sido coletada em áreas de restinga, mata de encosta e área antrópica no estado da Bahia. Curiosamente, a espécie não foi incluída por Mondin \& Bringel (2010) na lista da Flora do Brasil, corroborando a fragilidade entre os limites taxonômicos ainda pouco explorados da espécie.

É facilmente confundida com C. candolleana, espécie amplamente distribuída, e desta diferenciase basicamente pela lâmina foliar maior (4-8vs. 1,5$3 \mathrm{~cm}$ compr.), elíptica ( $v s$. oblonga ou triangular), pubescente ( $v s$. glabro a glabescente) e receptáculo epaleáceo (vs. paleáceo) (Fig. 4a-i).

8. Calea pinheiroi H. Rob., Phytologia 44(4): 272. 1979. Tipo: BRASIL. BAHIA: Delfino, $161 \mathrm{~m} \mathrm{NW}$ of Lagoinha (which is 5,5 $\mathrm{km} \mathrm{SW}$ of Delfino) on side road to Minas do Mimoso, Serra do Curral Feio, 4120'W, 10²2'S, 08.III.1974, R.M. Harley, S.A. Renvoize, C.M. Erskine, C. A. Brighton \& R. Pinheiro 17020 (Holótipo: US!; Isótipo: CEPEC!).

Fig. 5a-b

Arbusto ca. $25 \mathrm{~cm}$ alt.; ramos estrigosos. Folhas opostas, cartáceas, lâmina foliar 1,5-2,5× 1-2 cm, ovada, obtusa, crenada, truncada, estrigosas, subsésseis, pecíolo 3-5 $\mathrm{mm}$ compr. Sinflorescência terminal, cimosa, corimbiforme; capítulos congestos, pedúnculo até $6 \mathrm{~cm}$ compr. Capítulo discóide, homógamo; invólucro campanulado, 9-10×4-5 mm; brácteas involucrais 4-5 séries, verdes, margem hialina, glabras, as mais externas $2-3 \times 2 \mathrm{~mm}$., ovadas, arredondadas, as mais internas 5-6 $\mathrm{mm} \times 1 \mathrm{~mm}$ compr., elípticas, obtusas; receptáculo cônico, epaleáceo. Flores do disco 8 , corola ca. 3,5 mm compr. (tubo da corola $1,3 \mathrm{~mm}$ compr.), amarela, anteras ca. $2 \mathrm{~mm}$ compr., estilete dilatado na base, $4-5 \mathrm{~mm}$ compr. Cipsela 4 costelas, 2,5-3 mm compr., esparsamente estrigosa, carpopódio decorrente nas costelas; páleas do pápus 16-18, lives, subiguais, ca. 0,5 mm compr., ovadas.

Calea pinheiroié uma espécie conhecida apenas do seu holótipo procedente da caatinga no Recôncavo
Sul, Bahia (Hind \& Miranda 2008). Contudo, segundo Mondin \& Bringel (2010), C. pinheiroi ocorre em áreas de cerrado nos estados de Bahia e Minas Gerais. Acredita-se que a descrição e ilustração inédita dessa espécie no presente trabalho, juntamente com estudos revisivos no gênero, possam reconhecer sua extensão geográfica mais precisamente.

Dentre as espécies com capítulos discóides, C. pinheiroi diferencia-se pela lâmina foliar ovada, crenada, truncada, sinflorescência corimbosa com mais de três capítulos e carpopódio decorrente nas costelas (Fig. 5a-b).

9. Calea purpurea G.M. Barroso, Sellowia 26: 110. 1975. Tipo: BRASIL. BAHIA: Barreiras, Serra do Espigão Mestre, 06.III.1972, W.R. Anderson, M. Stieber, J.H. Kirkbride Jr 36632 (Isótipo: CEPEC!).

Fig. $5 c-h$

Subarbusto $40-50 \mathrm{~cm}$ alt.; ramos vilosos. Folhas opostas, discolores, membranáceas, lâmina foliar 1-2x 0,7-1 cm, elíptica, denteada, decorrente, estrigosa, sésseis a subsésseis, pecíolo até $2 \mathrm{~mm}$ compr. Sinflorescência terminal, cimosa, corimbiforme; capítulos congestos, pedúnculo 3-5 mm compr. Capítulo discóide, homógamo; invólucro cilíndrico 6$8 \times 2-3 \mathrm{~mm}$; brácteas involucrais 3 -séries, atropurpúreas, margem hialina, glabras, as mais externas ca. $2 \times 2 \mathrm{~mm}$, ovadas, arredondadas, as mais internas ca. $5 \times 2 \mathrm{~mm}$, elípticas, obtusas; receptáculo levemente cônico, epaleáceo. Flores 3, corola 3,5-4 mm compr., tubo (1 $\mathrm{mm}$ compr.), atropurpúrea, estames ca. $2 \mathrm{~mm}$ compr., estilete dilatado na base, 4-5mm compr. Cipsela 4costada, 4,5-5 mm compr., glabra, carpopódio decorrente nas costelas, páleas do pápus ca. 16, fundidas na base, subiguais, ca. $0,1 \mathrm{~mm}$ compr., escamiformes.

Material examinado: Barreiras, 26.I.2005, J. PaulaSouza et al. 4686 (HUEFS). Formosa do Rio Preto, 8.IV.1989, R.C. Mendonça et al. 1365 (US). Luiz Eduardo Magalhães, 29.XI.2003, B.A. Anjos et al. 183 (ALCB).

Material adicional examinado: GOIÁS. Lizarda, Rio das Pratas, 25.III.1978, C.A. Miranda 175 (HRB); $10^{\circ} 39^{\prime}$ S, 465'' $\mathrm{W}$, 22.IV.1978, R.P. Orlandi 89 (HRB).

Mondin \& Bringel (2010) citaram Calea purpurea como endêmica do estado da Bahia e esse trabalho reconhece a espécie com tendo distribuição centrada em áreas de cerrado e solo arenoso no extremo oeste da Bahia e Goiás.

Dentre as espécies com capítulos discóides, Calea purpurea diferencia-se das demais, principalmente, pelos capítulos com 3 flores, brácteas involucrais e flores atropurpúreas e páleas do pápus fundidas na base e inconspícuas (ca. 0,1 mm compr.) (Fig. 5c-h). 


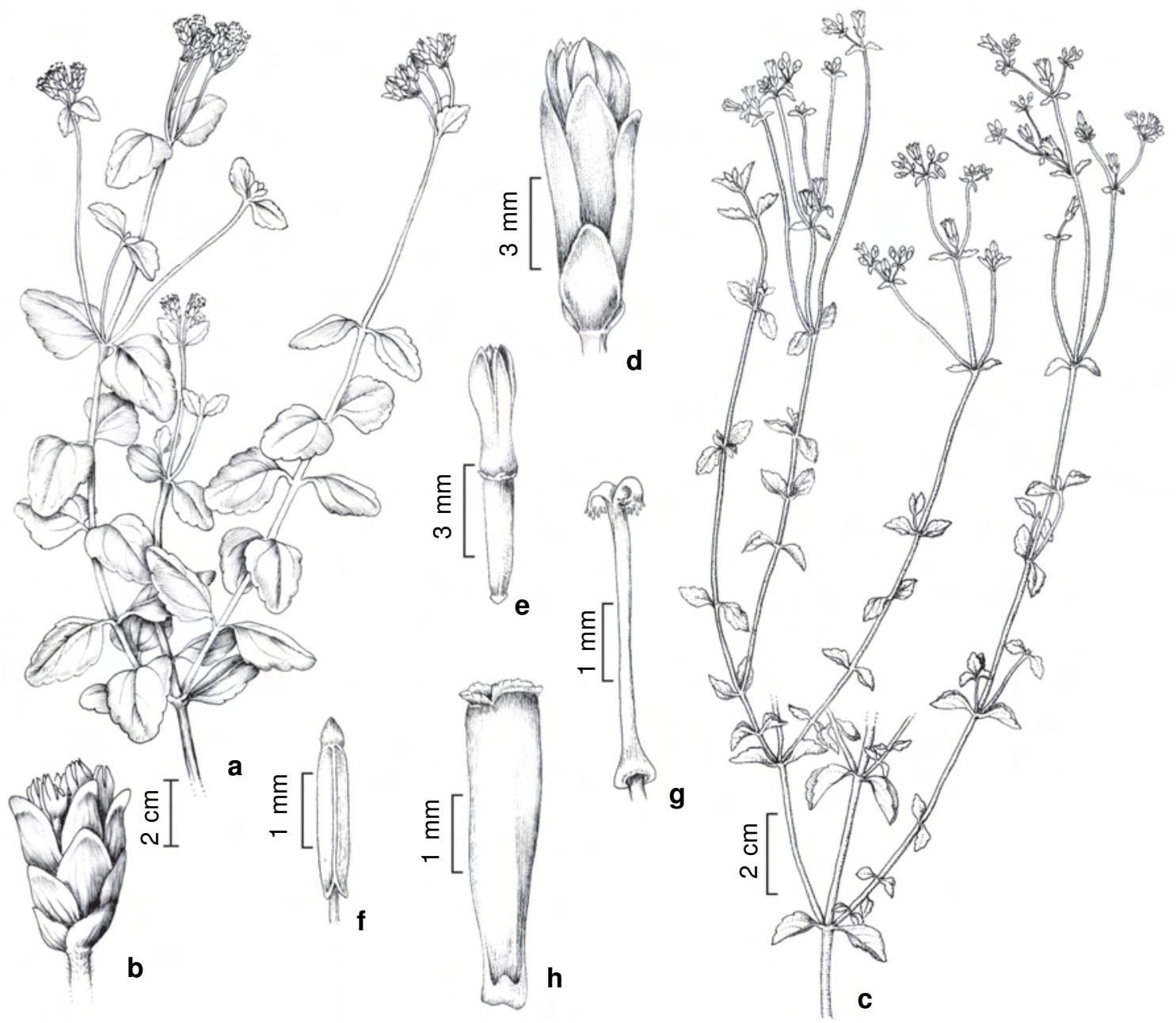

Figura 5 - a-b. Calea pinheiroi H. Rob.- a. ramo florido; b. capítulo discóide (Harley et al. 17020). c-h. Calea purpurea G.M. Barroso - c. ramo florido; d. capítulo discóide; e. flor do disco; f. estame; g. estilete; h. cipsela (Anjos et al. 183).

Figure 5 - a-b. Calea pinheiroi H. Rob. - a. flowering shoot; b. discoid head (Harley et al. 17020). c-h. Calea purpurea G.M. Barroso - c. flowering shoot; d. disc head; e. disc floret; f. stamen; g. style; h. cypselae (Anjos et al. 183).

10. Calea villosa Sch. Bip. ex Baker, Fl. bras. 6(3): 262. 1884. Síntipo: BRASIL. GOIÁS: "in campis arenosis inter S. Pedro et Nostra Senhora d'Abadia", G. Garden 4243 (Tipo: K) e "praeterea", Pohl 450 (Tipo: B; Foto: US!).

Fig. 6a-g

Subarbustos ou arbustos, $0,3-1 \mathrm{~m}$ alt.; ramos velutinos. Folhas opostas, discolores, papiráceas, lâmina foliar 1-2(2,5) ×0,5-1,3(1,5) cm, ovada, aguda a obtusa, serreada, atenuada, velutinas, sésseis a subsésseis, pecíolo até $5 \mathrm{~mm}$ compr. Sinflorescência terminal, cimosa, umbeliforme; capítulos laxos, sésseis a pedunculados, pedúnculo até $1,5 \mathrm{~cm}$ compr. Capítulo radiado, heterógamo, com 1-2 séries de brácteas foliáceas na base, ovadas, obtusas, ca. $5 \times$ $3 \mathrm{~mm}$, vilosas; invólucro campanulado, $0,8-1 \times 0,8$
$1 \mathrm{~cm}$; brácteas involucrais 4-séries, verdes, margem hialina, glabras, as mais externas 3-6 6 2,5-3 mm, obovadas, arredondadas, pubescentes, as mais internas $0,7-1 \times 0,4-0,5 \mathrm{~mm}$, obovadas a elípticas, arredondadas; receptáculo levemente côncavo, paleáceo, páleas 5-7 × 1-2 mm, lanceoladas a elípticas, aristadas, conduplicadas, persistentes. Flores do raio ca. 10, 1-1,2 cm compr., corola ca. 7 $\mathrm{mm}$ compr. (tubo ca. $2 \mathrm{~mm}$ compr.); flores do disco ca. 20,7-9 mm compr., corola $4-5 \mathrm{~mm}$ compr (tubo $1,0-1,5 \mathrm{~mm}$ compr.), amarela, anteras ca. $2 \mathrm{~mm}$ compr., estilete dilatado na base, ca. $5 \mathrm{~mm}$ compr. Cipsela 4-costada, 4,5-4 mm compr., glabra, carpopódio decorrente nas costelas; páleas do pápus ca. 11, livres, subiguais, ca. 0,5 mm compr., elípticas. 
Material examinado: Abaíra, 1319'S, 4151'W, 25.X.1993, W. Ganev 2627 (HUEFS, SPF, US). Catolés, 29.XI.1999, A.S. Conceição et al. 479(HUEFS). Correntina, 25.IV.1980, R.M. Harley 21755 (CEPEC). Piatã, 27.II.2009, M.L. Guedes et al. 14628(ALCB). Rio de Contas, 29.X.1988, R.M. Harley et al. 25747 (CEPEC, HUEFS, SPF, US). Seabra, $12^{\circ} 18 \mathrm{~S}$, 4150, 3.IX.1997, H.P. Bautista \& J. Oubiña 2248 (HRB).

Material adicional examinado: MINAS GERAIS. Grão Mogol, 14.II.2003, F. França et al. 4373 (HUEFS).

Calea villosa ocupa áreas com solos arenosos, argilosos e afloramentos rochosos em vegetação de campos rupestres, cerrados de altitude, campos gerais e carrascos nos estados de Goiás, Bahia e Minas Gerais.

Callea villosa assemelha-se a C. microphylla pelo tamanho reduzido das folhas e capítulos curto- pedunculados. No entanto distingue-se pelo indumento das folhas (face adaxial velutina $v s$. glabrescente), número de flores por capítulo (30 vs. 15) e tamanho do pápus (0,5mm vs. 0,2 mm compr.), respectivamente (Fig. 6a-g).

\section{Agradecimentos}

Os autores agradecem a todas as pessoas e instituições que colaboraram para a conclusão deste trabalho, especialmente aos curadores dos herbários visitados que permitiram a análise e empréstimo do material depositado. Ao Natanael Nascimento a arte e ilustrações das espécies e aos pareceristas pelas críticas e sugestões ao manuscrito.

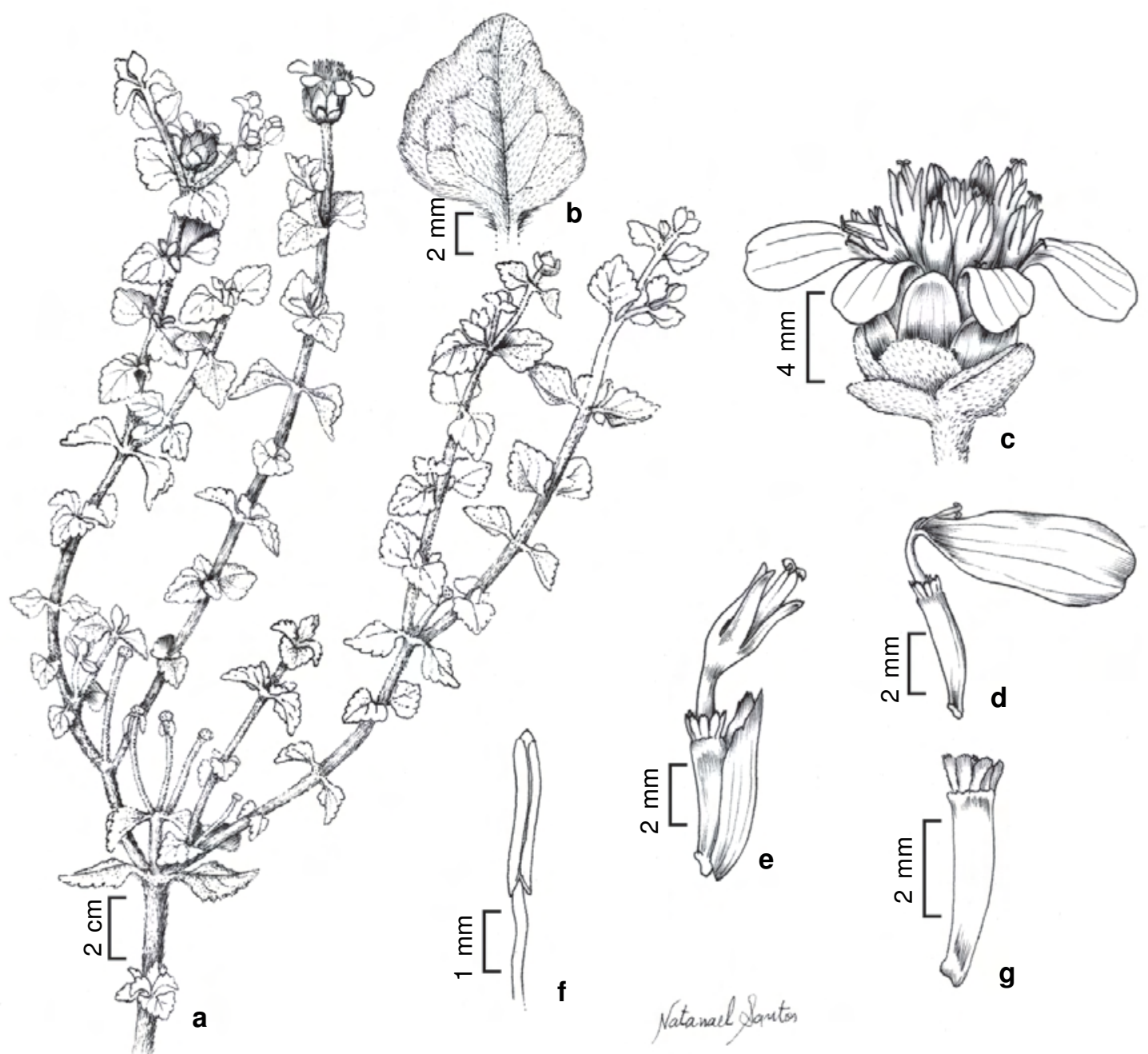

Figura 6 - Calea villosa Sch. Bip. ex Baker - a. ramo florido; b. folha (face adaxial); c. capítulo radiado; d. flor do raio; e. flor do disco e pálea do receptáculo; f. estame; g. cipsela (Harley et al. 25747).

Figure 6 - Calea villosa Sch. Bip. ex Baker - a. flowering shoot; b. adaxial leaf; c. radiate head; d. Ray floret; e. disc floret and receptacle pale; f. stamen; g. cypselae (Harley et al. 25747). 


\section{Referências}

Baker, J.G. 1884. Compositae: Helianthoideae. In: Martius C.F.P. von, Eichler, A.W. \& Urban, I. Flora brasiliensis. Munchen, Wien, Leipzig 6: 251-268.

Baldwin, B. G. 2009. The Heliantheae Alliance. In: Funk, V.A.; Susanna, A.; Stuessy, T.F. \& Bayer, R.J. (eds.). Systematics, evolution, and biogeography of the Compositae. IAPT, Vienna. Pp. 689-711.

Blake, S.F. 1930. Notes on certain type specimens of American Asteraceae in European herbaria. Contributions from the United States National Herbarium 26: 258.

Bremer, K. 1994. Asteraceae - cladistics \& classification. Timber Press, Portland.

Funk, V.A.; Susanna, A.; Stuessy, T. \& Bayer, R.J. (eds.). 2009. Systematics, evolution, and biogeography of the Compositae. IAPT, Vienna.

Hind, D.J.N. \& Miranda, E.B. 2008. Lista preliminar da família Compositae na Região Nordeste do Brasil. Royal Botanic Gardens, Kew.

Holmgren, P.K.; Holmgren, N.H. \& Barnett, L.C. 1990. Index Herbariorum. Part I: the herbaria of the world. New York Botanical Garden. New York. 693p.

Magenta, M.A.G. 1998. As subtribos Ambrosiinae, Galinsoginae e Coreopsidinae (Heliantheae Asteraceae) no estado de São Paulo. Dissertação de Mestrado. Universidade de São Paulo, São Paulo. 140p.

Mondin, C.A. \& Bringel Jr., J.B.A. 2010. Calea. In: Forzza, R.C. et al (eds.). Lista de espécies da flora do Brasil. Jardim Botânico do Rio de Janeiro. Disponível em < http://floradobrasil.jbrj.gov.br/2010/ FB103751>. Acesso em 16 Out 2010.

Panero, J.L. 2007. Heliantheae Alliance: Tribe Neurolaeneae Rydb. In: Kadereit, J.W. \& Jeffrey, C. (eds.). Families and genera of vascular plants. Vol. 8. Flowering plants. Eudicots. Asterales. Kubitzki's authoritative encyclopedia of vascular plants. Springer-Verlag, Berlin, Heidelberg. Pp. 417-420.

Panero, J.L. 2007a [2006]. Key to the tribes of the Heliantheae alliance. In: Kadereit, J.W. \& Jeffrey, C. (eds.). The families and genera of vascular plants. Vol. 8. Flowering plants. Eudicots. Asterales. Springer, Berlin. Pp. 391-395.

Panero, J.L. 2007b [2006]. Neurolaeneae. In: Kadereit, J.W. \& Jeffrey, C. (eds.). The families and genera of vascular plants. Vol. 8. Flowering plants. Eudicots. Asterales. Springer, Berlin. Pp. 417-420.
Panero, J.L. \& Funk, V.A. 2008. The value of sampling anomalous taxa in phylogenetic studies: Major clades of the Asteraceae revealed. Molecular Phylogenetics and Evolution 47: 757-782.

Pruski, J.F. 1984. Calea brittoniana and Calea kiristiniae: two new Compositae from Brazil. Brittonia 36: 98-103.

Pruski, J.F. 1998. Novelties in Calea (Compositae: Heliantheae) from South America. Kew Bulletin 53: 683-693.

Pruski, J.F. \& Urbatsch, L.E. 1988. Five new species of Calea (Compositae: Heliantheae) from Planaltine Brazil. Brittonia 40: 341-356.

Pruski, J.F. \& Hind, D.J.N. 1998. Two new species of Calea (Compositae: Heliantheae) from Serra do Grão Mogol and vicinity, Minas Gerais, Brazil. Kew Bulletin 53: 695-701.

Radford, A.E.; Dickison, W.C.; Massey, J.R. \& Bell, C.R. 1974. Vascular plants systematics. Harper \& Row Pub., New York. 891p.

Roque, N. \& Bautista, H.P. 2008. Asteraceae: caracterização e morfologia floral. Edufba, 79p.

Roque, N.; Keil, D.J. \& Susanna, A. 2009. Illustrated glossary of Compositae. Appendix A. In: Funk, V.A.; Susanna, A.; Stuessy, T. \& Bayer, R.J. Systematics, evolution and biogeography of the Compositae. IAPT, Vienna. Pp. 781-806.

Robinson, H. 1975. Studies in the Heliantheae (Asteraceae). VI. Additions to the genus Calea. Phytologia 32: 426-431.

Robinson, H. 1979a. Studies in the Heliantheae (Asteraceae). XXII. Two new species of Calea from Brazil. Phytologia 44: 436-441.

Robinson, H. 1979b. Studies in the Heliantheae (Asteraceae). XIX. Four new species of Calea from Brazil. Phytologia 44: 270-279.

Robinson, H. 1980. Studies in the Heliantheae (Asteraceae). XXVII. A new species of Calea from Brazil. Phytologia 47: 261-263.

Robinson, H. 1981. Studies in the Heliantheae (Asteraceae). XXVIII. Additions to Calea and Ichthyothere from Brazil. Phytologia 49: 10-13.

Urbatsch, L.E; Zlotsky, A. \& Pruski, J.F. 1986. Revision of Calea sect. Lemmatium (Asteraceae: Heliantheae) from Brazil. Systematic Botany 11: 501-514.

Wussow, J.R.; Urbatsch, L.E. \& Sullivan, G.A. 1985. Calea (Asteraceae) in Mexico, Central America and Jamaica. Systematic Botany 10: 241-267. 